NASA/TM-2007-214846

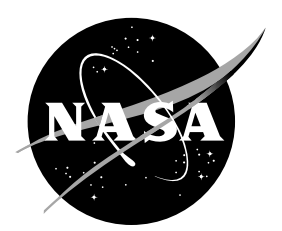

\title{
Spherical Cryogenic Hydrogen Tank Preliminary Design Trade Studies
}

Steven M. Arnold

Glenn Research Center, Cleveland, Ohio

Brett A. Bednarcyk

Ohio Aerospace Institute, Cleveland, Ohio

Craig S. Collier and Phillip W. Yarrington

Collier Research Corporation, Hampton, Virginia 


\section{NASA STI Program . . . in Profile}

Since its founding, NASA has been dedicated to the advancement of aeronautics and space science. The NASA Scientific and Technical Information (STI) program plays a key part in helping NASA maintain this important role.

The NASA STI Program operates under the auspices of the Agency Chief Information Officer. It collects, organizes, provides for archiving, and disseminates NASA's STI. The NASA STI program provides access to the NASA Aeronautics and Space Database and its public interface, the NASA Technical Reports Server, thus providing one of the largest collections of aeronautical and space science STI in the world. Results are published in both non-NASA channels and by NASA in the NASA STI Report Series, which includes the following report types:

- TECHNICAL PUBLICATION. Reports of completed research or a major significant phase of research that present the results of NASA programs and include extensive data or theoretical analysis. Includes compilations of significant scientific and technical data and information deemed to be of continuing reference value. NASA counterpart of peer-reviewed formal professional papers but has less stringent limitations on manuscript length and extent of graphic presentations.

- TECHNICAL MEMORANDUM. Scientific and technical findings that are preliminary or of specialized interest, e.g., quick release reports, working papers, and bibliographies that contain minimal annotation. Does not contain extensive analysis.

- CONTRACTOR REPORT. Scientific and technical findings by NASA-sponsored contractors and grantees.
- CONFERENCE PUBLICATION. Collected papers from scientific and technical conferences, symposia, seminars, or other meetings sponsored or cosponsored by NASA.

- SPECIAL PUBLICATION. Scientific, technical, or historical information from NASA programs, projects, and missions, often concerned with subjects having substantial public interest.

- TECHNICAL TRANSLATION. Englishlanguage translations of foreign scientific and technical material pertinent to NASA's mission.

Specialized services also include creating custom thesauri, building customized databases, organizing and publishing research results.

For more information about the NASA STI program, see the following:

- Access the NASA STI program home page at http://www.sti.nasa.gov

- E-mail your question via the Internet to help@sti.nasa.gov

- Fax your question to the NASA STI Help Desk at 301-621-0134

- Telephone the NASA STI Help Desk at 301-621-0390

- Write to: NASA Center for AeroSpace Information (CASI) 7115 Standard Drive Hanover, MD 21076-1320 
NASA/TM-2007-214846

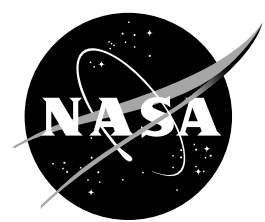

\section{Spherical Cryogenic Hydrogen Tank Preliminary Design Trade Studies}

Steven M. Arnold

Glenn Research Center, Cleveland, Ohio

Brett A. Bednarcyk

Ohio Aerospace Institute, Cleveland, Ohio

Craig S. Collier and Phillip W. Yarrington

Collier Research Corporation, Hampton, Virginia

Prepared for the

48th Structures, Structural Dynamics, and Materials Conference cosponsored by the AIAA, ASME, ASCE, AHS, and ASC

Waikiki, Hawaii, April 23-26, 2007

National Aeronautics and

Space Administration

Glenn Research Center

Cleveland, Ohio 44135 
This report contains preliminary findings, subject to revision as analysis proceeds.

Trade names and trademarks are used in this report for identification only. Their usage does not constitute an official endorsement, either expressed or implied, by the National Aeronautics and Space Administration.

This work was sponsored by the Fundamental Aeronautics Program at the NASA Glenn Research Center.

Level of Review: This material has been technically reviewed by technical management.

Available from

NASA Center for Aerospace Information 7115 Standard Drive

Hanover, MD 21076-1320
National Technical Information Service 5285 Port Royal Road Springfield, VA 22161 


\title{
Spherical Cryogenic Hydrogen Tank Preliminary Design Trade Studies
}

\author{
Steven M. Arnold \\ National Aeronautics and Space Administration \\ Glenn Research Center \\ Cleveland, Ohio 44135 \\ Brett A. Bednarcyk \\ Ohio Aerospace Institute \\ Cleveland, Ohio 44142 \\ Craig S. Collier and Phillip W. Yarrington \\ Collier Research Corporation \\ Hampton, Virginia 23666
}

\begin{abstract}
A structural analysis, sizing optimization, and weight prediction study was performed by Collier Research Corporation and NASA Glenn on a spherical cryogenic hydrogen tank. The tank consisted of an inner and outer wall separated by a vacuum for thermal insulation purposes. HyperSizer (Collier Research and Development Corporation), a commercial automated structural analysis and sizing software package was used to design the lightest feasible tank for a given overall size and thermomechanical loading environment. Weight trade studies were completed for different panel concepts and metallic and composite material systems. Extensive failure analyses were performed for each combination of dimensional variables, materials, and layups to establish the structural integrity of tank designs. Detailed stress and strain fields were computed from operational temperature changes and pressure loads. The inner tank wall is sized by the resulting biaxial tensile stresses which cause it to be strength driven, and leads to an optimum panel concept that need not be stiffened. Conversely, the outer tank wall is sized by a biaxial compressive stress field, induced by the pressure differential between atmospheric pressure and the vacuum between the tanks, thereby causing the design to be stability driven and thus stiffened to prevent buckling. Induced thermal stresses become a major sizing driver when a composite or hybrid composite/metallic material systems are used for the inner tank wall for purposes such as liners to contain the fuel and reduce hydrogen permeation.
\end{abstract}

\section{Introduction}

NASA is investing in technology development efforts and alternate fuel foundation technologies that will greatly reduce or even eliminate environmentally harmful emissions. Because of this, liquid hydrogen (LH2) has emerged as a propellant to supply the fuel needs for future aircraft due to its high energy per unit mass. Durable, lightweight cryogenic propellant storage and feed systems are required to enable the development of hydrogen-fueled aircraft. As a result, there is a need for hydrogen tank storage systems for these aircraft applications, which are expected to provide sufficient capacity for flight durations ranging from a few minutes to several days. It is understood that the development of a large, lightweight, reusable cryogenic liquid storage tank is crucial to meet the goals of and supply power to hydrogen-fueled aircraft, especially for long flight durations. For short-duration flight applications, simple tank designs may suffice. However, for longer duration flight applications, a double-wall construction with a vacuum-based insulation system appears to be the most optimum design 1, 2. Current preliminary mission requirements that are pushing the long-flight-duration hydrogen aircraft development include 
14-day (336-hr) flight duration with a payload capacity that is sufficient to accommodate the instrumentation required for the various missions. It is precisely these types of aircraft with relatively long flight durations on the order of days that provide the greatest engineering challenges to develop long-term and lightweight hydrogen storage systems, since boiloff of the cryogenic fluid can become a significant problem. For example, space shuttle operation accepts a loss rate (boiloff) of approximately 1.6 percent of LH2 by weight per hour, whereas for long flight duration aircraft applications an acceptable rate of boiloff of LH2 would be on the order of 0.1 percent by weight per hour.

Consequently, the need for reduced weight in combination with good insulating properties for longterm storage provides a new challenge for cryogenic tank design. These new designs provide an opportunity to apply advanced materials and structural concepts in an effort to reduce the overall weight of the tank and keep the volume at an acceptable and practical level. Although, the design of a cryogenic LH2 storage tank, coupled with the use of LH2 as aircraft fuel, involves many challenges, the most dominate structural ones include geometry, temperature, permeation, hydrogen embrittlement, and safety factors as reviewed recently by Mital et al. (ref. 1). In the present study we will revisit prior work (refs. 1 and 2) and perform preliminary material and structural trade studies on a doubled-walled, vacuum jacketed, spherical cryogenic tank concept; wherein 1) increased factors of safeties, 2) reduced strain allowables to prevent leakage are imposed, 3) multiple failure criteria, 4) metallic inner tank liner materials are introduced, and 5) additional materials are utilized for the sizing of both inner and outer tanks.

\section{Basic Design Considerations}

Multiple design configurations can be, and have been, envisioned from a single tank with insulation to hybrid tanks with either insulating materials or pure vacuum in between walls or various combinations thereof (ref. 1). The overall objective of the designs is to have a safe, lightweight, thermally efficient cryogenic storage system. Some important tank system parameters relative to flight durations are presented in table 1 . The materials, tank structural configurations, and insulation system options are numerous and interdependent. Some of these key considerations are: 1) the functional requirement that $\mathrm{LH} 2$ be maintained between its freezing and boiling points, $-259^{\circ} \mathrm{C}\left(-435^{\circ} \mathrm{F}\right)$ and $-253{ }^{\circ} \mathrm{C}\left(-423^{\circ} \mathrm{F}\right)$, respectively; 2) the temperature difference between ambient conditions and LH2, which can be as high as $\left.\Delta T=300^{\circ} \mathrm{C}\left(540^{\circ} \mathrm{F}\right) ; 3\right)$ tank wall and/or liner permeation by hydrogen or just leakage of the hydrogen through micro-cracks thus greatly impacting material selection of the tank wall and/or the need for a liner; and 4) the CTE mismatches between the components of the tank system. There are other important issues associated with cryogenic tank design such as vapor management (a proper vent system), fuel transfer, pumping a saturated cryogenic fluid such as LH2, and the possibility of the cold energy utilization. However, these system design issues are beyond the scope of this paper and thus will not be addressed here.

TABLE 1.-IMPORTANT TANK SYSTEM PARAMETERS RELATIVE TO FLIGHT DURATION

\begin{tabular}{|l|c|}
\hline [Listed in order of importance.] \\
\hline $\begin{array}{l}\text { Short flight } \\
\text { duration }\end{array}$ & $\begin{array}{c}\text { Mass density } \\
\end{array}$ \\
& $\begin{array}{c}\text { Strength and toughness } \\
\text { Coefficient of thermal expansion } \\
\text { Stiffness } \\
\text { Thermal diffusivity } \\
\text { Thermal conductivity }\end{array}$ \\
\hline $\begin{array}{l}\text { Long } \\
\text { flight } \\
\text { duration }\end{array}$ & Mass density \\
& Thermal conductivity \\
& Strength and toughness \\
& Coefficient of thermal expansion \\
& Stiffness \\
& Thermal diffusivity \\
\hline
\end{tabular}


One approach, to reduce the number of design choices is to turn to the concept of performance indices (e.g., material and structural), as put forth by Ashby (ref. 3); where the performance, $P$, of a structural element is a function of three, typically independent, aspects: the functional requirements, $F$, the geometry, $G$, and the properties of the material, $M$, of which it is made,

$$
P=\mathrm{f}(F, G, M)
$$

When this group of parameters is assumed to be separable, then

$$
P=\mathrm{f}_{1}(F) \cdot \mathrm{f}_{2}(G) \cdot \mathrm{f}_{3}(M)
$$

In this case the functions, $\mathrm{f}_{1}, \mathrm{f}_{2}$, and $\mathrm{f}_{3}$ are assumed to be independent of each other; that is, the optimal choice of materials is independent of the geometry of the structural component; thus enabling one to identify the optimal subset of materials without solving the complete design problem. While this is clearly a simplification of the full coupled design problem, it can provide a great deal of insight in the preliminary design stage. The key material indices applicable for both thermal and mechanical issues of interest here are shown in table 2. Constructing material property diagrams [see refs. 1 and 3] for examples], enable one to assess the pertinent thermal and mechanical performance indices given in table 2 and provide insight in designing an efficient insulation scheme for long duration flights. These diagrams also aid in narrowing the viable choices of engineering materials to be used.

TABLE 2.-PERFORMANCE INDICES FOR THERMAL AND MECHANICAL COMPONENTS OF CRYOGENIC STORAGE TANK

\begin{tabular}{|l|c|}
\hline \multicolumn{1}{|c|}{ Function and constraints } & Performance index, maximize \\
\hline Minimum heat flux at steady state, fixed thickness & $1 / \mathrm{k}$ \\
\hline $\begin{array}{l}\text { Minimum temperature rise in specified time, fixed } \\
\text { thickness }\end{array}$ & $1 / \mathrm{a}$ \\
\hline $\begin{array}{l}\text { Maximum energy stored for given temperature rise and } \\
\text { time }\end{array}$ & $\mathrm{k} / \alpha^{1 / 2}$ \\
\hline Minimum thermal distortion & $\mathrm{k} / \alpha$ \\
\hline \multicolumn{2}{|c|}{ Mechanical } \\
\hline Strength-limiting design with minimum mass \\
\hline Damage-tolerant design with minimum mass & $\sigma_{\mathrm{f}} / \rho$ \\
\hline Deformation-limiting design with minimum mass & $\mathrm{K}$ Ic $/ \rho$ \\
\hline
\end{tabular}

$\mathrm{k}=$ thermal conductivity

$a=$ thermal diffusivity $\left(k / \rho C_{p}\right)$

$\rho=$ mass density

$C_{p}=$ specific heat

$\alpha=$ coefficient of thermal expansion

$\sigma_{\mathrm{f}}=$ strength

$K_{I c}=$ mode I fracture toughness

$E=$ Young's modulus

Time, $\mathrm{t}=\mathrm{w}^{2} / 2 \mathrm{a}$ with $\mathrm{w}=$ wall thickness. 
Additional basic design considerations for the LH2 tank are discussed below:

\section{Thermal Insulation}

The four thermal performance indices come into play when considering designs concepts involving single or multiple layers of insulating materials. However, these types of concepts typically require large volumes of materials. Therefore, to deal with the significant thermal challenges the current state of the art suggests that a high vacuum with highly polished wall surfaces, with or without a multi layer insulation (MLI) system, can provide the required insulation needs for lightweight long-term cryogenic fluid storage applications. The MLI provides additional insulation against radiation heat transfer relative to a simple vacuum jacket system. However, either system is very sensitive and dependent on maintaining a very high level of vacuum, as any degradation in the vacuum level significantly degrades the systems insulating properties, thus potentially leading to mission failure.

\section{Tank Wall Material Selection}

When selecting tank wall material one can see from table 2 that the most desirable materials will possess high specific strength, high specific fracture toughness, and high specific stiffness, as well as low permeability to liquid and gaseous hydrogen; however, no single material provides all these attributes simultaneously. In Mital et al. (ref. 1) it was demonstrated that continuous-fiber-reinforced polymer (CFRP) composites, discontinuous reinforced metallic composites (DRX)-specifically discontinuous reinforced aluminum (DRA) (ref. 4), and metallic materials offer the best compromise relative to the performance indices. Note, however, that the use of continuous fiber reinforced composite materials most likely will involve higher initial manufacturing costs, while DRAs are essentially isotropic and can be manufactured using less expensive techniques such as casting. Furthermore DRA materials have the added benefit of extremely low (if not negligible) hydrogen gas permeability, an issue typically associated with polymer matrix composite systems. Ceramic materials also offer high specific strength, stiffness and low permeability, but because of their low fracture toughness they are not considered viable for tank wall material.

Two other key material properties that are important considerations for the design of high-pressure vessels but may also be applicable to low-pressure cryogenic storage tanks are yield-before-break, $K_{\mathrm{I} c} / \sigma_{y}$, and the leak-before-break, $\left(K_{\mathrm{I} c}\right)^{2} / \sigma f$, performance indices. Higher fracture toughness materials are desirable as they provide more damage-tolerant systems. Any crack that propagates into the insulation system can compromise the thermal properties of the insulation system-resulting in the loss of the mission due to rapid boiloff of the cryogenic fuel. It should be noted that composite materials, in general, provide high specific fracture toughness, which makes them desirable for this application. Yet, fracture toughness can become an issue especially at cryogenic temperatures, where many materials become excessively brittle.

Lastly, there is an advantage in using monolithic materials for tank construction since using one material for the tank wall eliminates thermally induced internal stresses due to different CTE factors of various materials such as the typical constituents of a composite material. However, most likely monolithic metallic tanks will not be as light as their PMC or DRX counterparts. Consequently, a metallic structure is fine for ground-based systems where weight is not as significant of a constraint as it is for any mobile or flight (be it aeronautics or space-based) hardware systems. It has been estimated that composites can offer a 25 percent weight savings relative to the latest monolithic aluminum tanks in these applications (ref. 5). Although, the resins used with polymer matrix composites do tend to allow higher hydrogen permeation than metals; thus leading to the recent investigation into advanced nanoclay enhanced resins discussed in reference 2 . 


\section{Tank Wall Architecture}

Although material selection for the tank wall is a critical issue in the design process, tank wall geometry (albeit single-wall or double-wall construction) is another interrelated issue. Various tank wall geometries have been utilized in the past 1 , however, due to the long duration missions of interest here most likely the insulation system utilized would be a high vacuum-based system which would dictate the use of a double-walled tank construction. As such, herein, we will only examine a doubled-walled vacuum jacketed spherical tank system. Clearly, the shape of the tank will affect its ability to accommodate bending stresses which will arise from fuel slosh and loads induced at the supports. Therefore, certain geometrical shapes, such as a sphere, can minimize bending stresses better within the wall of the tank, while cylindrical configurations or more complex conformal geometries may require selection of a wall construction that can accommodate bending.

\section{Liner}

A linerless tank (a tank without the need for a liner) is the preferred choice in order to minimize cost, weight, and compatibility issues. However, for advanced fiber-reinforced composites, even the state-ofthe-art resin systems (ref. 2) may be too permeable to contain liquid and gaseous hydrogen when subjected to high strains resulting from mechanical and thermal loads that are characteristic of efficient tanks. In addition, the thermal cycling associated with repeated filling and draining may cause material fatigue damage in the form of matrix microcracking, which may result in the leakage of hydrogen. And since composite spherical tanks are subjected predominantly to biaxial stresses, which may result in transverse microcracking at levels of strain significantly below the strain to failure, thin metallic or nonmetallic liners may be required. In addition, since all polymeric resins are gas permeable to a certain degree, metallic liners will be considered in the trades conducted herein.

\section{Structural Analysis Approach}

Herein, a structural analysis, sizing optimization, and weight prediction study is performed on a spherical cryogenic hydrogen tank. The tank consists of an inner and outer wall separated by a vacuum for thermal insulation purposes. The outer tank provides the vacuum jacket and carries external atmospheric pressure, while the inner tank contains the cryogenic hydrogen under the operating internal pressure. The specific 106 in. diameter double-walled tank design analyzed herein contains a central rod support which passes through the center of the tanks, protruding through the tanks at the top and bottom poles and enables the elimination of globally induced thermal forces between tanks. The central rod support provides structural rigidity to the 102 in. diameter inner tank, a port for filling and draining propellant, and a means of mounting the tank to the vehicle. The central rod is approximately $10 \mathrm{ft}$ long, so that the rod extends from both poles approximately 9 in., allowing enough length for mounting hardware to attach the tank to the vehicle structure. It was assumed to have a 4 in. diameter (ref. 2).

Figure 1 depicts both the inner and outer walls of the tank via a transparency view of the corresponding finite element mesh. The color bands represent identified optimization zones which are the fundamental structural components that will be used by HyperSizer (see discussion in section II.A below). Each band (referred to as a "component" within HyperSizer) can be sized independently to a different design concept (i.e., different skin thickness, panel cross sectional dimensions, layup, etc.). In doing so, the lightest feasible tank for a given overall size and thermomechanical loading environment may be obtained by HyperSizer.

The inner tank wall is sized based on biaxial tensile stresses, resulting from applied internal pressure, which causes it to be strength driven, and an optimum panel concept need not be stiffened. However, the external tank wall is sized mechanically by the pressure differential between atmospheric pressure and the vacuum between the tanks, causing it to be stability driven and thus stiffened to prevent buckling. Other loadings that affect the design are vehicle accelerations. Design attempts to minimize detrimental effects 

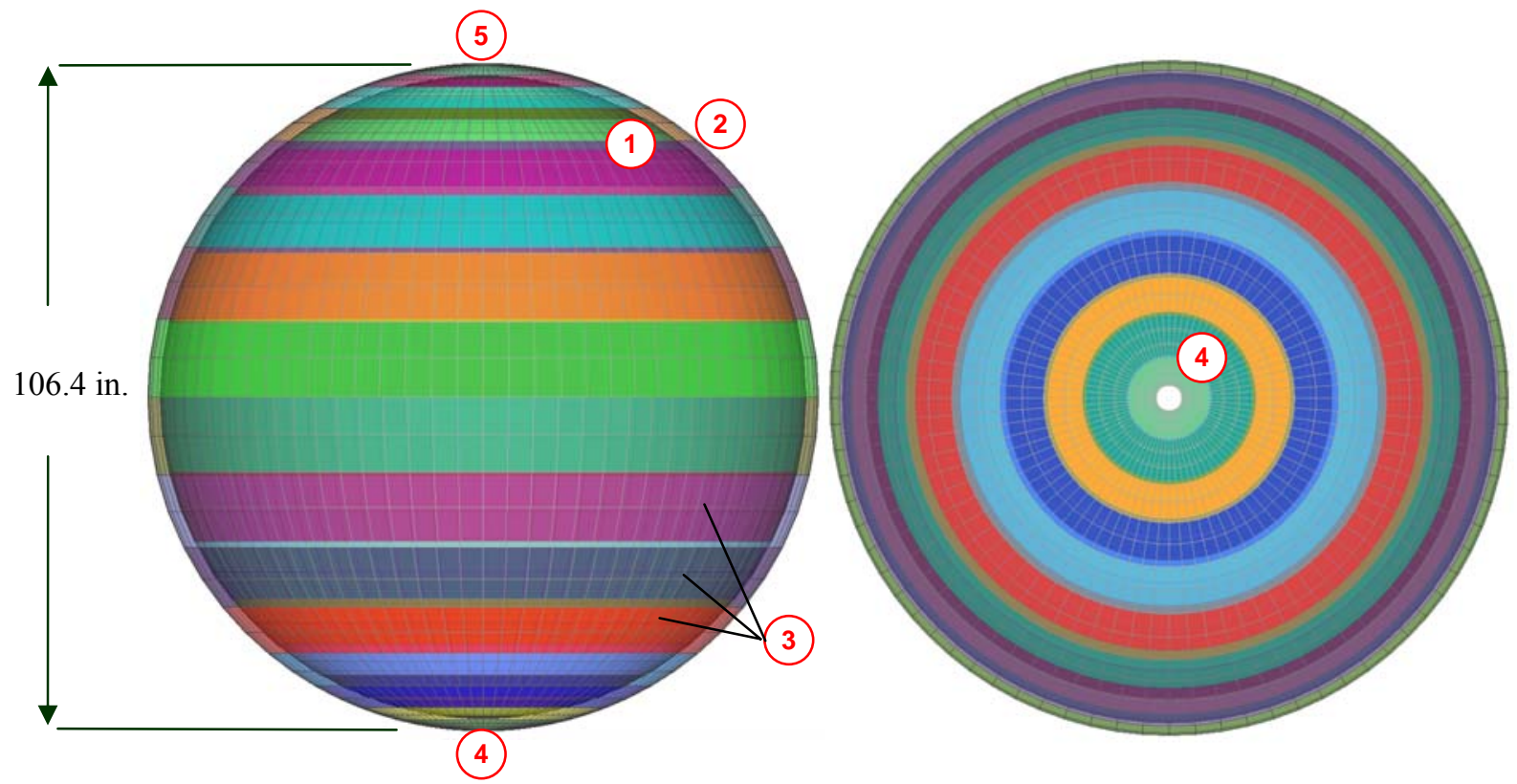

Figure 1.-A spherical cryogenic hydrogen tank analyzed and sized by HyperSizer, consisting of an (1)inner and (2)outer wall separated by a vacuum for thermal insulation purposes. Optimization zones are identified by the color bands (3). The left image is looking at the tank from the side, the right image is looking at the tank from the top/bottom. Supports are attached at the tank north(5) and south (4) poles. A column is placed vertically between the poles.

from tank supports were successful in reducing localized concentrated forces, however they did cause additional wall pad up and weights at the top and bottom tank poles caused primarily from vertical accelerations.

\section{A. Background on HyperSizer}

HyperSizer (ref. 6) is a structural analysis and sizing software tool developed by the Collier Research Corporation that automates the types of structural analyses that a typical aerospace stress engineer performs using closed-form, empirical based, and state-of-the-art numerical solutions. HyperSizer contains specialized aerospace structures knowledge and methods and provides a computational framework for performing non-FEA based analyses. However, the HyperSizer software seamlessly links with NASTRAN finite element models as well, so that loads can be extracted automatically, and then used to size a section of the structure, including the effects of stiffeners. If needed, HyperSizer can then update the NASTRAN model with new properties based on the sizing results of the section. The HyperSizer approach is to perform comprehensive failure analysis for all specified load cases and structural locations. These failure analyses are either not possible or not practical to perform with FEA. HyperSizer analyses are very rapid as panel concepts are analyzed without the need to discretely mesh with finite elements the shape of the stiffeners or their spacing. This permits tremendous flexibility and rapid turn around of trades with different panel concepts all from the same coarsely meshed global structural representation. Consequently, HyperSizer can find the lightest structural weight for a given set of candidate materials and panel concepts while ensuring that all potential failure modes are prevented from occurring during the sizing optimization.

Typical HyperSizer analyses consist of the following seven steps:

1. Use finite element mesh to define structural geometry

2. Assign material directionalities 
3. Apply boundary conditions

4. Apply load cases

5. Select material and panel concept constraints

6. Define failure criteria, limit and ultimate factors of safety, and buckling factors

7. Perform sizing analysis - where margins of safety are calculated throughout the structure

\section{B. Finite Element Model}

The NASTRAN finite element model employed was shown in figure 1. Both the inner and outer tanks were meshed with 6400 NASTRAN CQUAD4 shell elements; assuming a vacuum between the tanks. The interior post and beam support structure shown in figure 2 is meshed with 884 CBAR elements. This support structure is part of the inner tank with the purpose of carrying the imposed g-loads given in table 3. The effect of this support structure on the outer tank design is minimal. Figure 3 shows the assigned material direction for both tanks, where the preferred direction runs longitudinally from the north to south poles. Results from the NASTRAN finite element model were extracted by HyperSizer and applied to various sections ("components") of the tank. These components (colored circumferential bands) were shown in figure 1. In general, the HyperSizer software enables each component to be sized independently according to its local loads in order to minimize the overall weight of the structure. However, because the local loads in the components near the poles of the outer tank are highly dependent on the design of the attachments between the inner and outer tanks at the poles, the preliminary sizing of the outer tank was performed based solely on a component at the tank equator, the sizing component indicated in figure 3. Thus, the minimum acceptable unit weight (weight per unit area) determined by HyperSizer for this component was multiplied by the total outer tank area (i.e., $247 \mathrm{ft}^{2}$ ) to arrive at the estimate for the outer tank weight. Similarly, the weight estimate for the inner tank is established by multiplying the resulting weight per unit area by the total inner tank area of $228 \mathrm{ft}^{2}$.

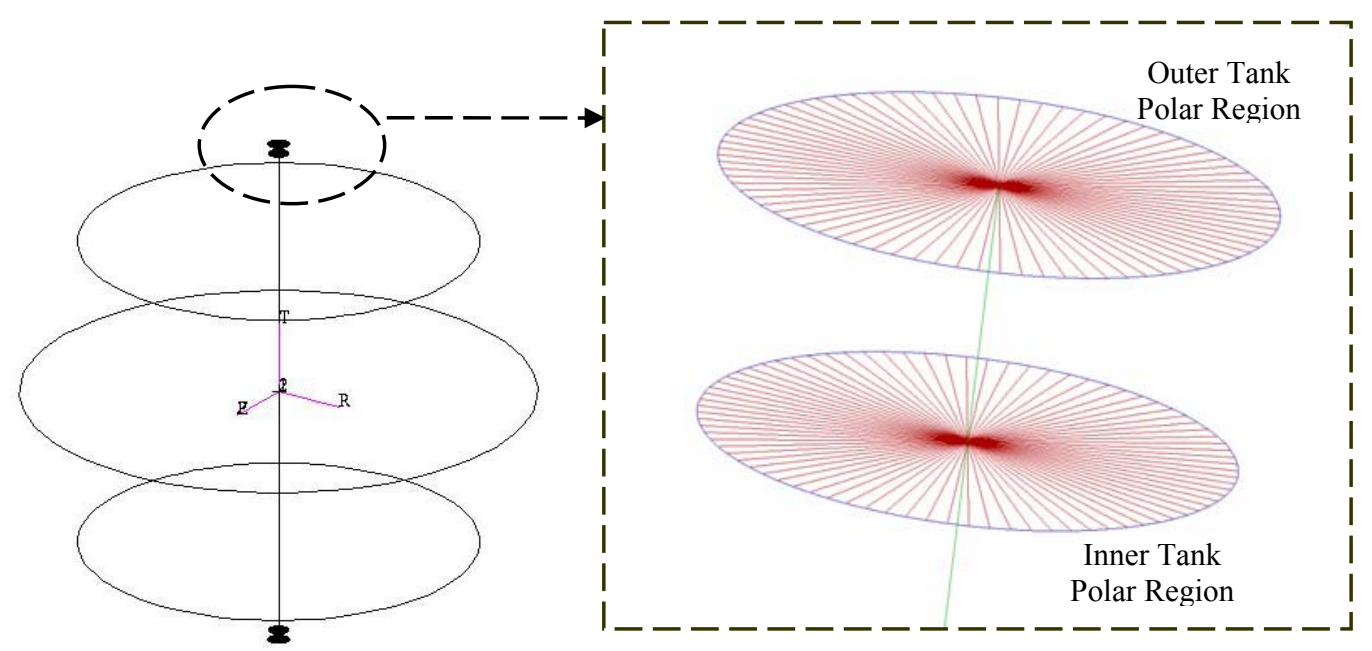

Figure 2.-Beam elements are used to transfer the vertical pole (green) and boundary condition concentrated forces to the four polar rings to support both inner and outer tank walls. 


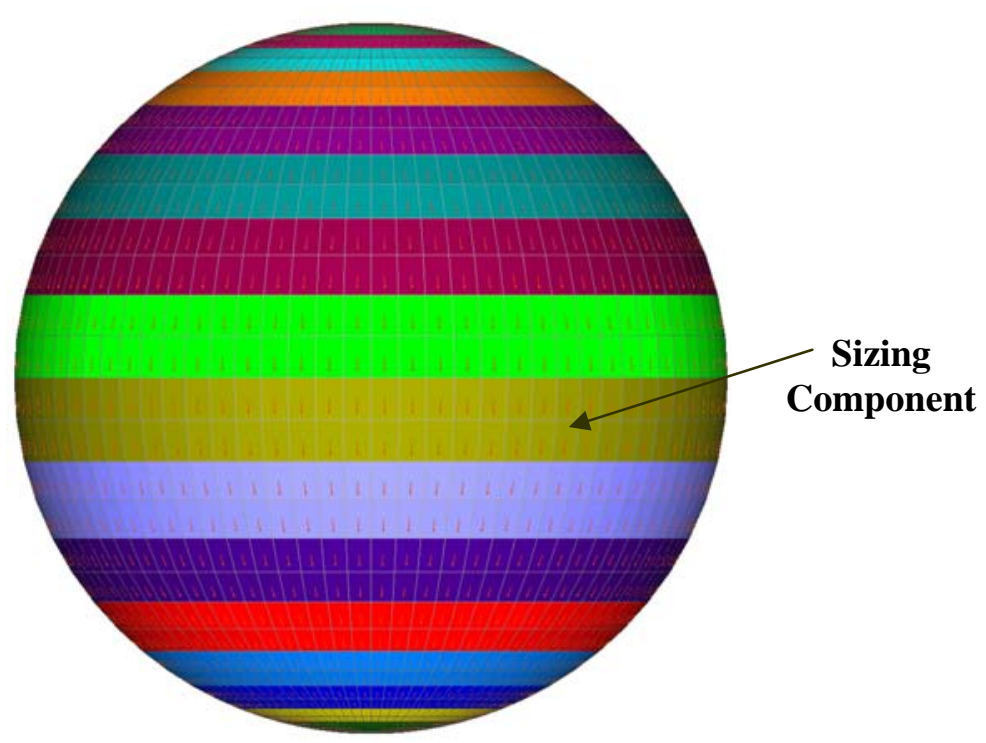

Figure 3.-HyperSizer graphics of material angles used to determine the direction of primary stiffening as well as the 0 degree reference for composite materials.

TABLE 3.-LOAD CASES

\begin{tabular}{|c|l|l|}
\hline LC & \multicolumn{1}{|c|}{ Loading } & \multicolumn{1}{|c|}{ Combined load sets } \\
\hline 1 & Static 30 psi internal fuel pressure & \\
\hline 2 & Static 14.7 psi external atmospheric pressure (worst case) & \\
\hline 3 & $4.5 g$ vertical acceleration - of the fuel & \\
\hline 4 & $4.5 g$ vertical acceleration - of the tank structure & \\
\hline 5 & $0.5 g$ lateral acceleration - of the fuel & \\
\hline 6 & $0.5 g$ lateral acceleration - of the tank structure & 3,4 \\
\hline 7 & Vertical acceleration (fuel + structure) & 5,6 \\
\hline 8 & Lateral acceleration (fuel + structure) & $3,4,5,6$ \\
\hline 9 & Total acceleration & $1,3,4$ \\
\hline 10 & Static $30 \mathrm{psi}+$ vertical acceleration & $1,5,6$ \\
\hline 11 & Static $30 \mathrm{psi}+$ horizontal acceleration & $1,3,4,5,6$ \\
\hline 12 & Static $30 \mathrm{psi}+$ total acceleration & \\
\hline 13 & Thermal: $-423^{\circ} \mathrm{F}$ internal tank, $72^{\circ} \mathrm{F}$ external tank & \\
\hline
\end{tabular}

\section{Load Factors, Failure Criteria, Buckling Factors, and Verification}

Mechanical loads on the tanks are derived from (1) the difference between the pressure within the tank and the ambient conditions, (2) fuel weight, (3) vehicle acceleration loads, (4) fuel slosh due to aircraft maneuvers, and (5) tank system weight and its supports. Fuel slosh is bound to be encountered as the aircraft maneuvers or as it encounters air turbulence during the flight. Consequently, six independent and seven combined load cases (LC) were examined as summarized in table 3 . The first six cases are the unique fundamental mechanical loadings cases. The $3.5 \mathrm{~g}$ anticipated acceleration is added to gravity for a net $4.5 \mathrm{~g}$ load vertical acceleration LC. With load cases 7 through 12 being derivative cases that are a combined superposition of the fundamental load cases, 1 through 6 . Case 13 is the thermal condition that is superimposed on all the mechanical conditions. The highlighted cases are the three controlling load cases that sized the inner and outer tanks. The outer tank wall is sized by LC 2 and the inner wall is sized by LC 12 and 13 superimposed. The other load cases were identified separately for early trade studies.

The pressures were applied to the NASTRAN FEM using PLOAD4 data type. This included the internal and external static pressures and the hydrostatic head from acceleration, i.e., head pressure $=$ density* acceleration* height of tank. The horizontal pressure was applied likewise. The dry mass of the 
walls were included as Non-Structural Mass (NSM) on the element data records and their inertia acceleration applied with GRAVITY data type. The NSM was entered automatically from HyperSizer.

Typically FEM is used to compute internal design-to forces; however in the present spherical tank problem the primary driving pressure induced hoop loads can be calculated without the need of FEA. Yet FEA is required to quantify wall forces due to acceleration loadings; however these loadings were found to produce only secondary effects. The inner wall internal (outward) pressure and outer wall external (inward) pressure can be determined quite accurately with closed form equations, below:

Internal wall running loads resulting from the 30 psi delta pressure.

$$
N_{X}=N_{y}=\frac{\operatorname{Pr}}{2}=\frac{30(51.19)}{2}=768(\mathrm{lb} / \mathrm{in})
$$

External wall running loads resulting from the -14.69 psi delta pressure.

$$
N_{X}=N_{y}=\frac{\operatorname{Pr}}{2}=\frac{-14.69(53.21)}{2}=-390.8(\mathrm{lb} / \mathrm{in})
$$

The thermally induced stresses, when applicable, can also be calculated in closed form without the need of FEA. HyperSizer automatically does this by using the materials thermal coefficients, elastic modulus, reference temperature, and operating temperature. This capability was used to quantify the resulting thermally-induced stresses between the composite and metallic liner.

Total mass and acceleration forces were verified with FEA diagnostic. The FEA solution was verified to have net zero forces on FEM grid constraints (SPC) for pressure, thus indicating that the loads were in balance and these same forces were equal to the closed form computed net force caused by acceleration. The FEA computed outer wall forces had an extremely slight variation in them (i.e., $\mathrm{N}_{\mathrm{x}}$ and $\mathrm{N}_{\mathrm{y}}$ ranged between 385 to $390 \mathrm{lb} /$ in.), the largest deviation being in the polar regions. The inner tank had larger, but still small variations in forces. The polar caps had bending moments that caused the inner wall to deform significantly when unstiffened. The solution was to stiffen these north and south pole regions. Similarly, the typical process of iterating between FEA and HyperSizer to obtain convergence of loading was done; in this case the issue is bending moments on the inner wall panels caused by vertical acceleration and the changing reference plane due to panel thickness sizing.

\section{Load Factors, Failure Criteria, Buckling Factors, and Verification}

\section{Load Factors}

A limit load factor of 1.33, and an ultimate load factor of 1.65 where utilized throughout the analysis. These factors are thought to be appropriate for pressurized vessels even though NASA typically uses an ultimate load factor of 2.0 for space flight pressure vessels. These factors are higher than those used in reference 2 , which used a limit load factor $=1.0$, and ultimate load factor of $=1.5$ in accordance with U.S. federal aviation regulations (U.S. FAA (ref. 7)), and had an impact of not only increasing the weight slightly but also modified the final selected stiffening concept for the outer tank.

\section{Composite Failure Criteria}

Different failure criteria are appropriate for different tank hardware. HyperSizer has a large body of test data embedded in its database associated with composite materials at cryogenic temperatures and has specific correlation factors for almost all commonly used failure criteria; with the Tsai-Hahn criteria having the best correlation to test data. Herein, seven failure criteria were examined during the analysis of 
the outer tank, i.e., maximum strain, maximum stress, Tsai-Hill, Tsai-Wu, Tsai-Hahn, Hoffman, and LaRC03. However, for the inner tank wall (which in stark contrast to the outer tank is subjected to cryogenic temperatures) a different composite analysis approach is required because of the need to reduce or eliminate permeation of the hydrogen due to thermally induced matrix cracking. Consequently, for this analysis, we chose to employ the maximum strain in the fiber direction as the failure criteria, with an imposed reduced strain allowable of 0.006 in./in.

\section{Panel Buckling}

Curved panel buckling analysis, a buckling knockdown factor and buckling lengths must be specified. The buckling knockdown factor is employed to correlate theoretical (Raleigh-Ritz) curved panel buckling loads (which are typically highly non-conservative) with experimental buckling loads. This is due to the fact that curved panel buckling is highly dependent on slight variations in thickness and flaws that occur randomly in structures. The necessary buckling knockdown factor is also a function of thickness, as the small variations and flaws become of greater importance as the structure becomes thinner (refs. 8 and 9). The buckling lengths characterize the controlling buckling mode shapes for the curved panel and are a function of the thickness and radius of curvature of the panel. These buckling lengths must be verified through an independent finite element analysis of the curved panel.

Given the fact that the outer tank is subjected to a state of biaxial compression and thus its sizing is stability driven, performing an accurate buckling analysis is critical. Consequently, due to the curvature of tank walls we chose to employ the cylindrical Raleigh Ritz energy solution contained within HyperSizer instead of the more commonly used flat plate closed form solution, even though the optimization run times are longer. Although, this cylindrical solution fully accounts for anisotropic panel stiffness's, it is limited to single curvature. Thus to account for the spherical shape, the buckling lengths were calibrated to FEA eigenvalue analyses. An FEA eigenvalue analysis was performed to measure the distance of the sphere half mode shapes which were assigned as a HyperSizer buckling length. In the case of a stiffened panel this length was 7 in., whereas in the unstiffened case it was 6 in., see figure 4 and table 4.
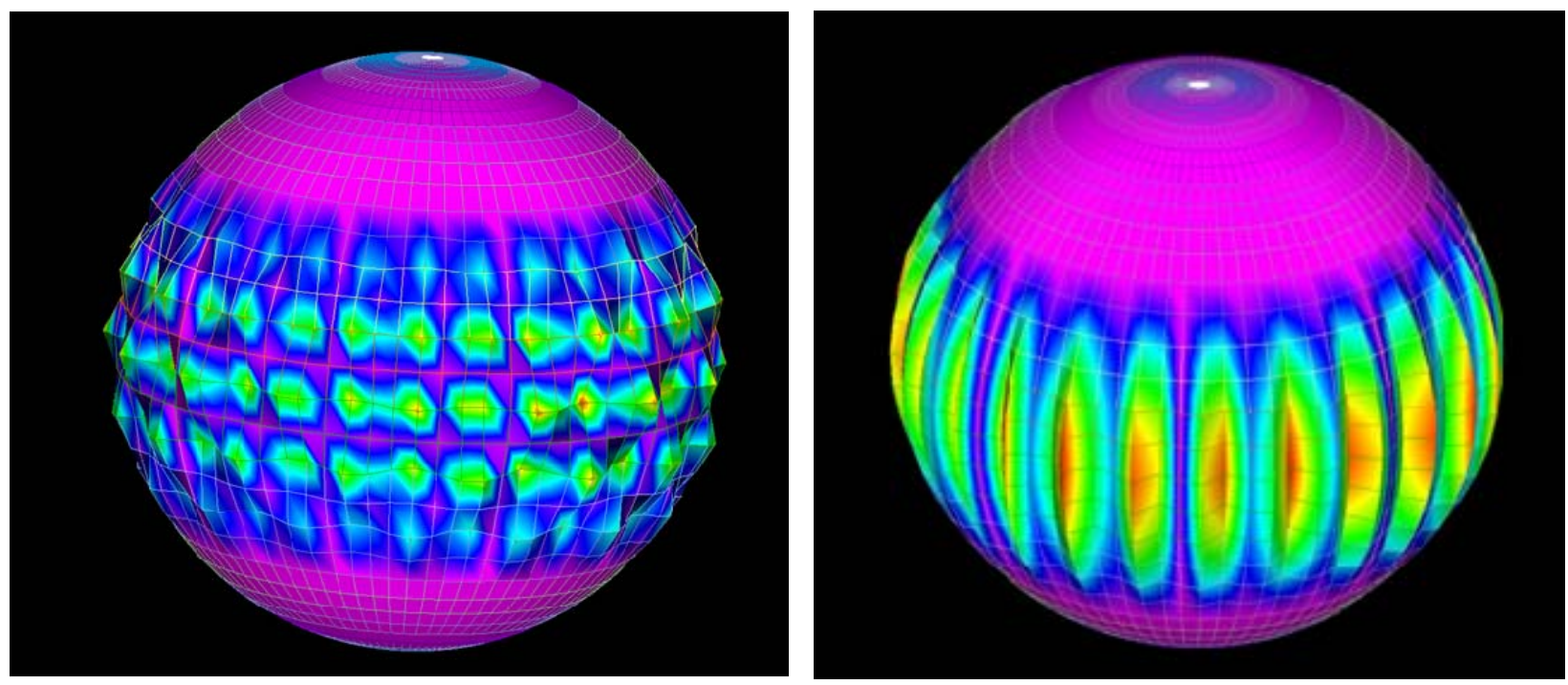

Figure 4.-FEA eigenvalue determination of appropriate buckling span for the outer wall. The left mode shape is for a stiffened panel that shows 7 in. half modes. The right mode shape is for an unstiffened panel and shows 6 in. modes. 
TABLE 4.-FACTORS OF SAFETY AND BUCKLING PARAMETERS USED IN THE OUTER TANK SIZING

\begin{tabular}{|c|c|c|c|c|}
\hline Concept & $\begin{array}{c}\text { Limit load factor } \\
\text { (Local buckling) }\end{array}$ & $\begin{array}{c}\text { Ultimate load factor } \\
\text { (Global buckling, } \\
\text { crippling) }\end{array}$ & $\begin{array}{c}\text { Buckling lengths } \\
\text { (in.) }\end{array}$ & $\begin{array}{c}\text { Buckling knockdown } \\
\text { factor }\end{array}$ \\
\hline Unstiffened & 1.33 & 1.65 & $6 \times 6$ & 0.4 \\
\hline Grid stiffened & 1.33 & 1.65 & $7 \times 7$ & 0.75 \\
\hline
\end{tabular}

Table 4 provides the factors of safety, buckling lengths, and buckling knockdown factors employed in the sizing of the outer tank. In HyperSizer, global buckling, such as panel buckling, crippling, and bucklingcrippling interaction are treated as ultimate failure events and thus employ the ultimate load factor. Local buckling, on the other hand, is a local failure event and the structure can typically support a great deal of additional load prior to collapse after the onset of local buckling as stresses are redistributed (ref. 10). Consequently, local buckling of the facesheet and the grid stiffeners within HyperSizer thus employ the limit load factor. The buckling knockdown factors employed are based on NASA SP8007 (ref. 8) which penalizes theoretical buckling loads as a function of the $(\mathrm{r} / \mathrm{t})$ ratio, which is radius divided by thickness. Furthermore, HyperSizer adds to the methods of NASA SP8007 by including the effects of the D11, D22, and D33 bending stiffness terms and reliability analysis, see reference 9 . These factors are different for the stiffened and unstiffened configurations because they have different effective thicknesses.

An assessment was also made as to whether the overall global linear elastic deformations of the inner and outer walls are compatible. The issue is the possible ballooning type deformation of the unstiffened inner wall due to internal pressurization, and a tear drop type deformation due to vertical acceleration and inertia of the fuel mass. The concern is that the inner tank wall will displace beyond the 2 in. clearance available between it and the outer tank wall, and thus bear against it. The correct analysis would entail a non-linear geometric FEA solution; however, this level of analysis detail is beyond the scope of the present paper. A non-linear FEA analysis (for the acceleration load case) however, would likely show deformations smaller than the linear elastic analysis, which computes displacements based on bending stiffness only of the panels and does not include membrane resistance to curvature (think of a sagging cable resisted by tensile forces). So for this reason, it is assumed that the linear static FEA analysis conservatively computes total, overall wall displacements. In the present case it showed a total displacement of the inner tank wall of only $0.39 \mathrm{in}$. This is well below the available $2 \mathrm{in}$. clearance between inner and outer tanks.

\section{E. Materials}

Given our initial screening of materials via the performance indices described earlier, four basic materials were selected for study. Three were isotropic metallic based materials (i.e., Al 2024, LiAl 2090, and DRA (with 20 percent and 55 percent particle volume content) and the fourth was a continuous graphite reinforced polymeric composite (i.e., IM7/977-2) with a fiber volume fraction of 60 percent. The material properties employed are given in table 5; where the IM7/977-2 system ply-level properties are given. The composition of the DRA material is Al-10Si-1Mg with 20 percent or 55 percent SiC particles (ref. 11).

Many different layup ply orientation percentages were attempted, but because of the biaxial nature of the hoop loading, the optimum layups tended to be those that had equal amounts of 0 and 90 degree plies. The layup that was settled on was an 8-ply quasi isotropic, symmetric laminate, i.e., [45/-45/0/90]s, where during sizing the individual ply thicknesses were uniformly scaled so as to achieve positive margins. Each ply utilized the properties given in table 5. It should also be noted that the allowables of the ply material, as given in table 5, have also been knocked down to account for matrix cracking, which must be avoided in a pressure vessel configuration. For our baseline inner tank wall we chose a more established material: Al $2024 \mathrm{~T} 81$. The $-423^{\circ} \mathrm{F}$ strength data used shows it to increase dramatically as compared to room temperature strength. This is questionable and could cause this material to be less weight competitive than currently quantified. Lastly since the external tank wall is subjected to a compressive state and thus stability driven, those materials in table 5 with high specific stiffness's, i.e., DRA and graphite/epoxy, should be the best outer tank candidate materials. 
TABLE 5.-MATERIAL PROPERTIES

\begin{tabular}{|c|c|c|c|c|c|c|c|c|}
\hline Property & \multicolumn{2}{|c|}{ LiAl 2090} & \multicolumn{2}{|c|}{ Al 2024 T81 } & $\begin{array}{c}\text { DRA } \\
20 \text { percent }\end{array}$ & $\begin{array}{c}\text { DRA } \\
55 \text { percent }\end{array}$ & \multicolumn{2}{|c|}{$\begin{array}{c}\text { Graphite/Epoxy* } \\
\text { IM7/977-2 Ply }\end{array}$} \\
\hline$\rho\left(\mathrm{lb} / \mathrm{in}^{3}\right)$ & \multicolumn{2}{|c|}{0.0975} & \multicolumn{2}{|c|}{0.11} & 0.099 & 0.11 & \multicolumn{2}{|c|}{0.057} \\
\hline & RT & $-423^{\circ} \mathrm{F}$ & RT & $-423^{\circ} \mathrm{F}$ & RT & RT & RT & $-423^{\circ} \mathrm{F}$ \\
\hline $\mathrm{E}_{1}$ tension $(\mathrm{Msi})$ & 11.6 & 12.9 & 10.5 & 11.8 & 15.7 & 29 & 23.3 & 20.8 \\
\hline $\mathrm{E}_{1}$ compression $(\mathrm{Msi})$ & 11.6 & 12.9 & 10.5 & 12 & 15.7 & 29 & 21.5 & 20.4 \\
\hline $\mathrm{E}_{2}$ tension $(\mathrm{Msi})$ & 11.6 & 12.9 & 10.5 & 11.8 & 15.7 & 29 & 1.35 & 2.8 \\
\hline $\mathrm{E}_{2}$ compression $(\mathrm{Msi})$ & 11.6 & 12.9 & 10.5 & 12 & 15.7 & 29 & 1.35 & 2.8 \\
\hline$v_{12}$ & 0.315 & 0.301 & 0.313 & 0.283 & 0.33 & 0.24 & 0.3 & 0.3 \\
\hline $\mathrm{G}_{12}(\mathrm{Msi})$ & 4.41 & 4.96 & 4 & 4.6 & 6.04 & 11.7 & 0.75 & 1.16 \\
\hline$\alpha\left(\times 10^{-6} /{ }^{\circ} \mathrm{F}\right)$ & 12.1 & 0.02 & 12.55 & 8.5 & 9.28 & 5.6 & $\begin{array}{c}\alpha_{\mathrm{L}}=-0.1 \\
\alpha_{\mathrm{T}}=15\end{array}$ & $\begin{array}{c}\alpha_{L}=-0.3 \\
\alpha_{T}=15\end{array}$ \\
\hline Stress Allowables & & & & & & & & \\
\hline$\sigma_{11}^{u}$ tension $(\mathrm{ksi})$ & 72.5 & 78 & 67 & 100 & 50 & 55 & 139.8 & 124.8 \\
\hline $\begin{array}{l}\sigma_{11}^{u} \text { compression } \\
(\mathrm{ksi})\end{array}$ & 72.5 & 78 & 67 & 100 & 50 & 55 & 129 & 122.4 \\
\hline$\sigma_{22}^{u}$ tension $(\mathrm{ksi})$ & 72.5 & 78 & 67 & 100 & 50 & 55 & 8.1 & 16.9 \\
\hline $\begin{array}{l}\sigma_{22}^{u} \text { compression } \\
(\mathrm{ksi})\end{array}$ & 72.5 & 78 & 67 & 100 & 50 & 55 & 8.1 & 16.9 \\
\hline$\sigma_{11}^{y}$ tension $(\mathrm{ksi})$ & 68.2 & 73 & 59 & 88 & 35 & 30 & 139.8 & 124.8 \\
\hline $\begin{array}{l}\sigma_{11}^{y} \text { compression } \\
(\mathrm{ksi})\end{array}$ & 68.2 & 73 & 59 & 88 & 35 & 30 & 129 & 122.4 \\
\hline$\sigma_{22}^{y}$ tension $(\mathrm{ksi})$ & 68.2 & 73 & 58 & 88 & 35 & 30 & 8.1 & 16.9 \\
\hline $\begin{array}{l}\sigma_{22}^{y} \text { compression } \\
(\mathrm{ksi})\end{array}$ & 68.2 & 73 & 58 & 88 & 35 & 30 & 8.1 & 16.9 \\
\hline$\tau_{12}^{u}(\mathrm{ksi})$ & 54 & 54 & 40 & 39 & 39 & 39 & 11.6 & 15.8 \\
\hline
\end{tabular}

*Considered both standard and reduced (0.006 in./in.) strain allowables.

\section{Inner Tank Sizing Results}

Here sizing results are presented for the unstiffened portion of the inner tank wall. We begin by examining a representative acreage component, (see fig. 3), subjected to the fundamental load case 1 which results in biaxial circumferential tensile forces. Note no minimum gage constraint has been imposed on the facesheet or liner thicknesses, as only structural viability, and not permeability or manufacturability is being assessed. Table 6 shows the resulting panel unit weights considering the five materials given in table 5. Clearly, the graphite/epoxy, IM7/977-2, system is significantly lighter than the comparable metallic based designs as one might suspect since the specific strength of this PMC system is significantly greater than its metallic counterparts. Also when reduced strain allowables are utilized for the Gr/Ep system wall thickness is increased as is tank weight. Further it is interesting to note that a linerless IM7/977-2 concept (even when strain allowables are reduced to ensure no microcracking) is 23 percent lighter than the lightest of the Gr/Ep with metallic liner systems considered. 
TABLE 6.--RESULTS OF INNER TANK WALL TRADE STUDIES WHEN SUBJECTED TO 30 PSI INTERNAL PRESSURE ONLY AT RT

\begin{tabular}{|l|l|l|c|c|c|}
\hline \multicolumn{1}{|c|}{ Material } & $\begin{array}{c}\text { Material } \\
\text { thick } \\
\text { (in.) }\end{array}$ & \multicolumn{1}{|c|}{$\begin{array}{c}\text { Liner Matl and } \\
\text { thickness }\end{array}$} & $\begin{array}{c}\text { Total } \\
\text { thickness } \\
\text { (in.) }\end{array}$ & $\begin{array}{c}\text { Unit } \\
\text { weight } \\
\text { (psf) }\end{array}$ & $\begin{array}{c}\text { Weight } \\
\text { (lb) }\end{array}$ \\
\hline $\mathrm{Gr} / \mathrm{Ep}^{1}$ & 0.0154 & none & 0.0154 & 0.126 & 28.7 \\
\hline $\mathrm{Gr} / \mathrm{Ep}^{2}$ & 0.0198 & none & 0.0198 & 0.162 & 36.9 \\
\hline $\mathrm{Gr} / \mathrm{Ep}$ & 0.0154 & 0.00591 in. LiAL 2090 & 0.0213 & 0.2094 & 47.7 \\
\hline $\mathrm{Gr} / \mathrm{Ep}$ & 0.0154 & 0.00606 in. Al 2024 & 0.0215 & 0.2145 & 48.9 \\
\hline $\mathrm{Gr} / \mathrm{Ep}$ & 0.022 & 0.01667 in. DRA 20 percent & 0.0387 & 0.4182 & 95.3 \\
\hline $\mathrm{Gr} / \mathrm{Ep}$ & 0.044 & 0.01939 in. DRA 55 percent & 0.0634 & 0.6683 & 152 \\
\hline $\mathrm{LiAL} 2090$ & 0.0176 & NA & 0.0176 & 0.2467 & 56.2 \\
\hline $\mathrm{Al} 2024$ & 0.0189 & NA & 0.0189 & 0.2754 & 62.8 \\
\hline DRA 20 percent & 0.0292 & NA & 0.0292 & 0.4161 & 94.9 \\
\hline DRA 55 percent & 0.0341 & NA & 0.0341 & 0.5393 & 123 \\
\hline
\end{tabular}

${ }^{1} \mathrm{MS}$ for $\mathrm{Gr} / \mathrm{Ep}=\min$ of (max strain, Tsai-Hahn)

${ }^{2} \mathrm{MS}$ for $\mathrm{Gr} / \mathrm{Ep}=\min$ of (max strain, Tsai-Hahn), with reduced leak criteria strain allowable of 0.006 in./in. this is a baseline case w/o a liner

In order to demonstrate that the $30 \mathrm{psi}$ internal pressure is the dominant loading case for sizing the inner tank wall, a similar sizing analysis for the four metallic materials was conducted, but with the sizing component force resultants obtained via a finite element analysis using load case 12 of table 3 . Clearly, the resulting inner tank weights (see table 7) are increased by less than 7 percent thereby substantiating our earlier hypothesis, that acceleration loads produce only secondary effects.

TABLE 7.-SIZING RESULTS FOR INNER TANK WALL WHEN BOTH 30 PSI INTERNAL PRESSURE AND ALL ACCELERATIONS FROM TABLE 3, LOAD CASE 12, ARE EXAMINED AT ROOM TEMPERATURE

\begin{tabular}{|l|c|c|c|c|}
\hline \multicolumn{1}{|c|}{ Material } & $\begin{array}{c}\text { Material } \\
\text { thick } \\
\text { (in.) }\end{array}$ & $\begin{array}{c}\text { Total } \\
\text { thickness } \\
\text { (in.) }\end{array}$ & $\begin{array}{c}\text { Unit } \\
\text { weight } \\
\text { (psf) }\end{array}$ & $\begin{array}{c}\text { Weight } \\
\text { (lb) }\end{array}$ \\
\hline LiAL 2090 & Varies slightly & Varies slightly & Avg. 0.2610 & 59.5 \\
\hline Al 2024 & Varies slightly & Varies slightly & Avg. 0.2926 & 66.7 \\
\hline DRA 20 percent & Varies slightly & Varies slightly & Avg. 0.4424 & 101 \\
\hline DRA 55 percent & Varies slightly & Varies slightly & Avg. 0.5735 & 131 \\
\hline
\end{tabular}

As the inner wall (and not the outer wall) is subjected to a severe thermal environment, trade studies must be conducted under combined mechanical and thermal load histories. Note in general the stress allowable will be greater at cryogenic temperatures, (see table 5). Also, within HyperSizer thermo-elastic lamination theory is utilized to perform a ply-by-ply failure analysis wherein internal thermal residual stresses due to thermal expansion mismatch are account for. Table 8 presents inner tank weight results given a combined 30 psi internal pressure and a $-423{ }^{\circ} \mathrm{F}$ thermal loading. Note that the reduced leak criteria strain allowable of $0.006 \mathrm{in}$./in., for both RT (room temperature) and $-423^{\circ} \mathrm{F}$ temperatures, was applied. Interaction failure criteria are known to work well with RT material strength properties, but are questionable at cryogenic temperatures, as demonstrated by the fact that when the interaction criteria were turned on the laminate could not size due to internal thermal stresses. Consequently, for the combined thermal-mechanical case only the maximum strain failure theory was considered. When the maximum strain in the 1 direction (fiber direction) was activated the laminate sized strictly to fiber strain. Alternatively, when the maximum strain in the 2 direction was used, the laminate could not size again without exceeding the matrix strain allowable due to the thermal residual stress/strain developed from the 
large change in temperature. This explains why the baseline graphite/epoxy case without a liner found in table 8 has the same weight $(36.9 \mathrm{lb})$ as it does in table 6, i.e., in both cases, the inner tank was sized by the reduced 0.006 in./in. strain allowable. Thus it can be concluded that matrix cracking within the Gr/Ep system should be expected to occur just from thermal loading alone. Consequently, some type of liner material would be required to ensure no hydrogen permeation. This is in sharp contrast to the conclusion found in previous work (ref. 2) for a nanoclay enhanced resin system, wherein approximately 2.5 times the current matrix strain allowable was used.

TABLE 8.-RESULTS OF INNER TANK WALL MATERIAL AND UNSTIFFENED PANEL WEIGHT TRADE STUDIES. LOADING CONSISTS OF 30 PSI INTERNAL PRESSURE AND $-423^{\circ} \mathrm{F}$ TEMPERATURE DIFFERENTIAL. AREA $=228 \mathrm{ft}^{2}$

\begin{tabular}{|c|c|c|c|c|c|}
\hline Material & $\begin{array}{c}\text { Material } \\
\text { thickness } \\
\text { (in.) }\end{array}$ & $\begin{array}{c}\text { Liner } \\
\text { material thickness }\end{array}$ & $\begin{array}{c}\text { Total } \\
\text { thickness } \\
\text { (in.) }\end{array}$ & $\begin{array}{c}\text { Unit } \\
\text { weight } \\
\text { (psf) }\end{array}$ & $\begin{array}{c}\text { Weight } \\
\text { (lb) }\end{array}$ \\
\hline $\mathrm{Gr} / \mathrm{Ep}$ & 0.0198 & none & 0.0198 & 0.162 & 36.9 \\
\hline $\mathrm{Gr} / \mathrm{Ep}$ & 0.011 & $\begin{array}{c}0.01526 \text { in. } \\
\text { LiAL 2090 }\end{array}$ & 0.02626 & 0.3045 & 69.4 \\
\hline $\mathrm{Gr} / \mathrm{Ep}$ & 0.011 & $\begin{array}{c}0.00943 \text { in. } \\
\mathrm{Al} 2024\end{array}$ & 0.0204 & 0.2274 & 51.8 \\
\hline $\mathrm{Al} 2024$ & 0.01269 & $\mathrm{NA}$ & 0.01269 & 0.1845 & 42.0 \\
\hline $\begin{array}{l}\mathrm{LiAL} \\
2090\end{array}$ & 0.01636 & $\mathrm{NA}$ & 0.01636 & 0.2293 & 52.3 \\
\hline
\end{tabular}

As one might expect, the monolithic, Al 2024 T81, tank actually sized up to be 33 percent lighter at $-423{ }^{\circ} \mathrm{F}$ than at RT (i.e., $42 \mathrm{lb}$ versus $62.8 \mathrm{lb}$ ) due to the fact that the cryogenic strength properties are 50 percent higher than RT properties (see table 5). This increase in strength, however, is questionable as it was based on behavior of AL 2024 T81 tempered rod and bar forms per MIL-HDBK-5E (ref. 12). Note, however, in the case of Gr/Ep tanks with metallic liners the thickness of the metallic liners slightly increased (and thus the inner tank weight) as a result of the additional induced thermal stresses within the tank, compare table 6 with table 8. Lastly, due to the lack of cryogenic data for the DRA material no additional results beyond those of tables 6 and 7 can be reported for the imposed thermal environment. Furthermore, thermal material incompatibility prevented a workable design for the case of a DRA liner and $\mathrm{Gr} / \mathrm{Ep}$ inner tank.

\section{Outer Tank Sizing Results}

As stated earlier the outer tank wall is sized mechanically by the pressure differential between atmospheric pressure and vacuum (a biaxial compressive loading condition), causing the controlling failure analysis to be stability driven. Consequently, specific compressive stiffness, $E_{c} / \rho$, is more important than specific strength. One clear option to lighten the design is to stiffen the outer tank to prevent buckling. The grid stiffened structural concepts considered for the outer tank sizing are shown in figure 5. For comparison purposes an unstiffened uniform thickness concept, for each material was also considered. It should be noted that HyperSizer admits a great deal of freedom in optimizing the grid stiffened panels shown in figure 5. For instance, the iso-grid panel concept allows the grid stiffeners in each direction to be independent materials and have independent heights, thicknesses, and spacing. For the sizing performed in this section, many of these sizing variables were linked such that the entire panel was required to be the same material, while four independent geometric variables remained. These four independent geometric variables are: facesheet thickness, stiffener thickness, stiffener height, and stiffener spacing. HyperSizer optimizes the panel by varying these geometric variables, each within a specified range, while also varying the materials and or concepts in order to determine the lightest weight configuration that satisfies all failure analysis checks. Note that, since within a sphere the hoop loads are the same in both directions (with near zero in-plane shear) the angle-grid and bi-grid are essentially 

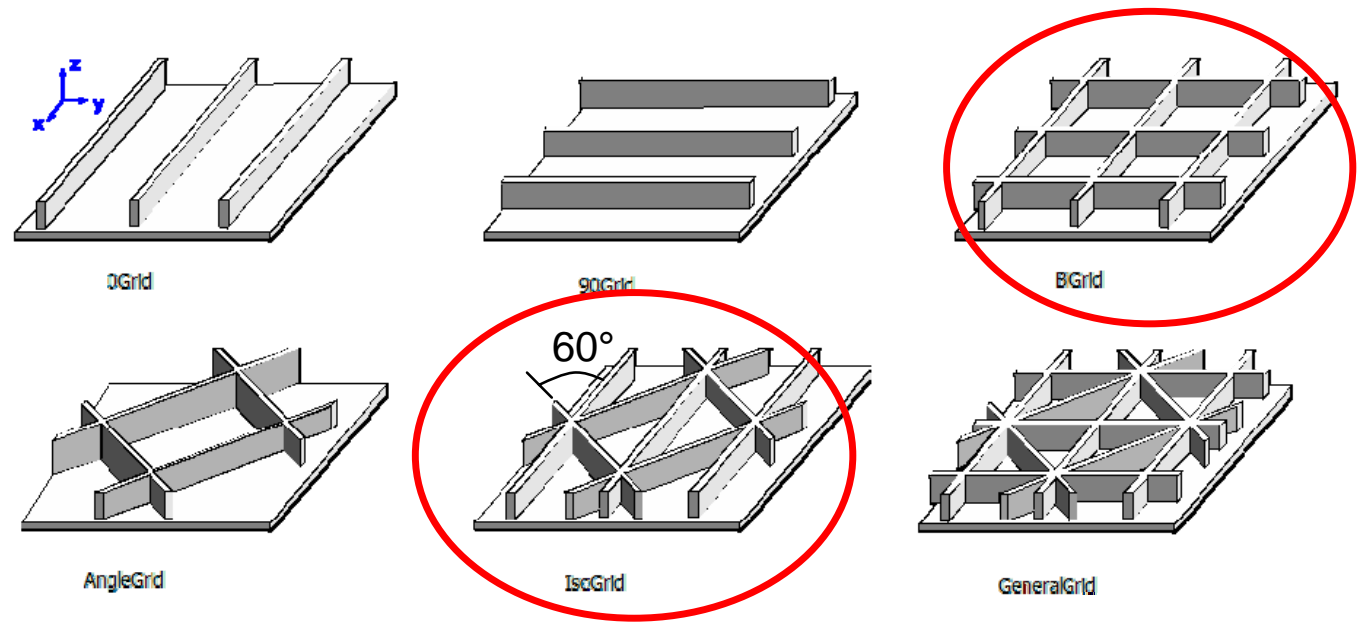

Figure 5.-HyperSizer grid stiffened panel concepts considered in the sizing of the outer tank.

equivalent designs; as it is merely a matter of orientation of the stiffening ribs in relation to the sphere, which has no effect. Consequently, HyperSizer would obtain the same optimum weight for either anglegrid or bi-grid concepts for the analytical biaxial loads (see eq. 3). Furthermore, note that both concepts may be slightly lighter and/or easier to fabricate than the iso-grid concept.

Sizing results of the outer tank are summarized in table 9, where the table is divided into stiffened and unstiffened configurations. Recall that the weight for each design is simply the unit weight determined by the HyperSizer sizing optimization multiplied by the tank area $\left(247 \mathrm{ft}^{2}\right)$. For the unstiffened configurations, the only design parameter is the tank thickness, and in all five cases curved panel buckling was the controlling failure mechanism. For the grid stiffened configurations, the four geometric design parameters are given in table 9. Further, the table indicates that a bi-grid configuration was chosen as the optimum for all materials except the graphite/epoxy system, which utilized an iso-grid configuration. In addition, the controlling failure mode for the stiffened LiAl 2090 was curved panel buckling, while for the Al 2024, DRAs and graphite/epoxy stiffened panels; the controlling failure mode was crippling-buckling interaction.

In terms of the weights for each outer tank designs, table 9 indicates that all stiffened configurations are lighter than all unstiffened configurations. The graphite/epoxy composite design was the lightest material choice for both the stiffened and unstiffened configurations; with the 55 percent DRA material system being a close second, especially in the stiffened configuration. Given the assumptions employed in the sizing analysis outlined previously, the iso-grid stiffened graphite/epoxy composite system provided the lowest overall weight at $108 \mathrm{lb}$. However, the 55 percent DRA and 20 percent DRA bi-grid configurations were also very lightweight at 111 and $129 \mathrm{lb}$, respectively and could possibly be a better choice if the manufacturing costs (likely dominated by machining (or casting) of the grid stiffeners) were significantly lower than the PMC composite manufacturing costs. Remember, these weights are for the acreage area of the tank, and do not include the closeout and fitting material required to withstand the localized forces at the tank attachments. The non-optimum weight factor within HyperSizer was set to 1.0, meaning these are ideal weights that do not include such closeout details and items such as weld fillets, brackets, clips, etc. Traditional non-optimum weight factors account for added weight and analysis inaccuracies. A range of 1.2 to 1.5 has been used in the past. However, we believe that HyperSizer is considerably more accurate than previous weight prediction analysis tools to the point where the nonoptimum weight factor should be based strictly on historical data that compares as fabricated weights to theoretical weights, and should not include analysis inaccuracy. For this reason, if one applies a weight non-optimum, it should be on the low range of traditionally used values. 
TABLE 9.-SUMMARY OF OUTER TANK DESIGNS PERFORMED AT RT

\begin{tabular}{|c|c|c|c|c|c|c|c|c|}
\hline \multirow{6}{*}{ 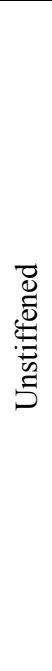 } & Design solution & $\begin{array}{c}\text { Unit } \\
\text { weight } \\
\left(\mathrm{lb} / \mathrm{ft}^{2}\right)\end{array}$ & $\begin{array}{l}\text { Weight } \\
\text { (lb) }\end{array}$ & $\begin{array}{c}\text { Facesheet } \\
\text { thickness } \\
\text { (in.) }\end{array}$ & $\begin{array}{c}\text { Stiffener } \\
\text { thickness } \\
\text { (in.) }\end{array}$ & $\begin{array}{c}\text { Stiffener } \\
\text { height } \\
\text { (in.) }\end{array}$ & $\begin{array}{c}\text { Stiffener } \\
\text { spacing } \\
\text { (in.) }\end{array}$ & $\begin{array}{c}\text { Controlling } \\
\text { failure } \\
\text { mode } \\
\end{array}$ \\
\hline & $\begin{array}{l}\text { Aluminum } \\
(\mathrm{LiAl} 2090)\end{array}$ & 1.862 & 460 & 0.1326 & ----- & ----- & ----- & $\begin{array}{l}\text { Curved } \\
\text { panel } \\
\text { buckling }\end{array}$ \\
\hline & $\begin{array}{l}\text { Aluminum } \\
(2024-\mathrm{T} 81)\end{array}$ & 1.973 & 487 & 0.1356 & ----- & ----- & ----- & $\begin{array}{l}\text { Curved } \\
\text { panel } \\
\text { buckling }\end{array}$ \\
\hline & DRA 20 percent & 1.691 & 418 & 0.1186 & ----- & ----- & ----- & $\begin{array}{l}\text { Curved } \\
\text { panel } \\
\text { buckling }\end{array}$ \\
\hline & DRA 55 percent & 1.490 & 368 & 0.0941 & ----- & ----- & ----- & $\begin{array}{l}\text { Curved } \\
\text { panel } \\
\text { buckling }\end{array}$ \\
\hline & $\begin{array}{l}\text { Graphite/ } \\
\text { epoxy }\end{array}$ & 1.246 & 307 & 0.1518 & ----- & ----- & ----- & $\begin{array}{l}\text { Curved } \\
\text { panel } \\
\text { buckling }\end{array}$ \\
\hline \multirow{6}{*}{ 总 } & $\begin{array}{l}\text { LiAl } 2090 \\
\text { (bi-grid) }\end{array}$ & 0.557 & 138 & 0.019 & 0.015 & 0.35 & 0.5 & $\begin{array}{l}\text { Curved } \\
\text { panel } \\
\text { buckling }\end{array}$ \\
\hline & $\begin{array}{l}\text { Al 2024-T81 } \\
\text { (bi-grid) }\end{array}$ & 0.606 & 150 & 0.019 & 0.016 & 0.36 & 0.5 & $\begin{array}{l}\text { Crippling- } \\
\text { buckling } \\
\text { interaction }\end{array}$ \\
\hline & $\begin{array}{l}\text { DRA } 20 \text { percent } \\
\text { (bi-grid) }\end{array}$ & 0.524 & 129 & $0.018 *$ & $0.014 *$ & 0.34 & 0.5 & $\begin{array}{l}\text { Crippling- } \\
\text { buckling } \\
\text { interaction }\end{array}$ \\
\hline & $\begin{array}{l}\text { DRA } 55 \text { percent } \\
\text { (bi-grid) }\end{array}$ & 0.448 & 111 & $0.017 *$ & $0.011 *$ & 0.31 & 0.6 & $\begin{array}{l}\text { Crippling- } \\
\text { buckling } \\
\text { interaction }\end{array}$ \\
\hline & $\begin{array}{l}\text { Graphite/ } \\
\text { epoxy } \\
\text { (iso-grid) }\end{array}$ & 0.436 & 108 & 0.033 & 0.0154 & 0.31 & 0.7 & $\begin{array}{l}\text { Crippling- } \\
\text { buckling } \\
\text { interaction }\end{array}$ \\
\hline & $\begin{array}{l}\text { Graphite/ } \\
\text { epoxy at }-70{ }^{\circ} \mathrm{F} \\
\text { (iso-grid) }\end{array}$ & 0.428 & 106 & 0.0242 & 0.0198 & 0.29 & 0.6 & $\begin{array}{l}\text { Crippling- } \\
\text { buckling } \\
\text { interaction }\end{array}$ \\
\hline
\end{tabular}

*A manufacturing minimum gage limit may need to be applied.

Recall that the sizing analysis performed on the outer tank did not consider any thermal loading. Yet from our inner tank work, one might suspect that the sizing of the outer tank, given a graphite/epoxy material system, would be affected by any temperature change as the graphite/epoxy plies exhibit thermal expansion mismatches that give rise to thermally induced stresses that combine with the mechanically induced stresses. Consequently, a single sizing analysis involving a $\mathrm{Gr} / \mathrm{Ep}$ outer tank at altitude (i.e., $65,000 \mathrm{ft}$ which results in an outer tank surface temperature of $-70^{\circ} \mathrm{F}$, see ref. 2) was conducted. The result is shown in the last row of table 9 , where it is clear that the resulting outer tank weight is slightly lower $(106 \mathrm{lb})$ as compared to the ground based, i.e., RT, weight of $108 \mathrm{lb}$. Thus indicating that ground conditions are controlling for the sizing of the outer tank and that microcracking due to thermally induced stresses, at altitude, is not a concern. 
Note, if minimum gage manufacturing limits are imposed the outer tank weight will increase significantly. For example, in the case of 55 percent DRA, when a minimum gage of 0.03 in. is imposed the outer tank weight increases from 111 to $160 \mathrm{lb}$ and the controlling failure mode would switch from crippling buckling interaction to that of face sheet local buckling. Also, note the weights in table 9 are based on membrane compressive forces, and do not include the outer fiber stresses/strain variations caused by secondary bending moments due to pressure on the facesheet skin as supported between the rib stiffeners. Since this is a strength driven effect, the DRA materials will still be better performing as compared to the Al 2024 and LiAL 2090 materials, but the advantage may not be as great. Including these additional stresses and strains may exceed the material's yield stress but not the materials ultimate stress; meaning the panel could withstand the loading without static failure. However, allowing the panel to go beyond the material yield could present a fatigue concern, and also in essence, the skin pockets would be in a post buckled mode shape that could present other operational disadvantages.

Lastly, the entire outer tank was sized (not just a representative acreage component) given the resulting FEA distribution of loadings. Figures 6, 7, and 8 illustrate the outer tank wall unit weight, margin of safety, and controlling failure mode distribution over the entire outer tank results, respectively. In figure 6 one clearly sees how the polar regions pad up (become thicker and thus heavier) to accommodate the increased loads in these regions due to bending and load transfer from the center post. Figure 7 depicts how uniform and close to zero (i.e., $\mathrm{MS}=0.001$ to 0.006 ) the margin of safety is over the entire outer tank wall, thus indicating the near optimum solution that was obtain. Finally, figure 8 shows that over 85 percent of the outer tank is controlled by crippling-buckling interaction failure criteria, while in the polar regions both strength and local buckling modes are controlling instead.
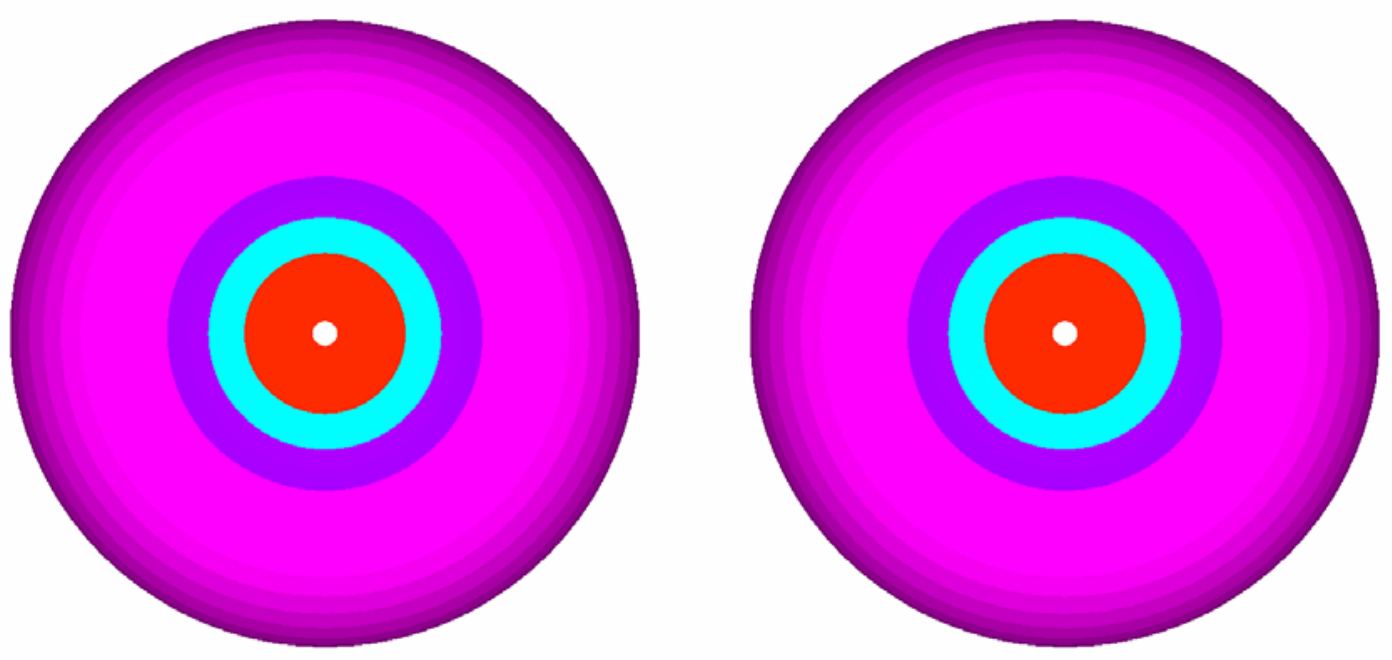

Figure 6.--Outer wall unit weights of iso-grid stiffened panel concept, wherein the magenta color indicates lightest weight and red the heaviest weight. Figure on left represents the north pole and the right side the south pole. 


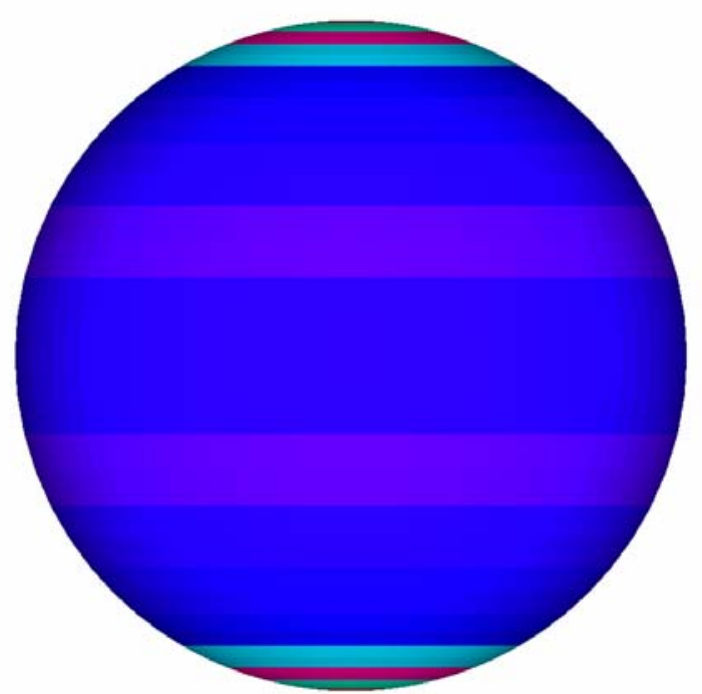

Figure 7.-Outer wall minimum margin-of-safety (MS) for all failure modes. Color variation shows a range of MS from 0.001 (blue) to 0.006 (orange), which are very desirable since they are close to zero. This shows a very near optimum solution on the entire tank wall.

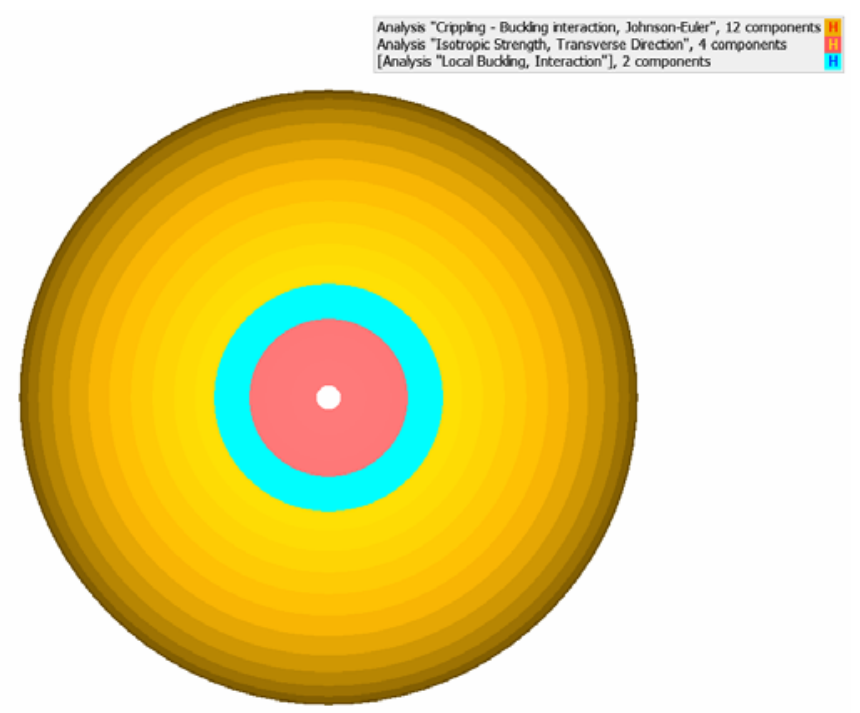

Figure 8.- Illustrates the controlling failure modes for the outer tank wall. Same result for opposite polar region. 


\section{Conclusion}

A structural analysis and sizing optimization study was performed on a doubled-wall spherical cryogenic hydrogen tank concept. The tank consists of an inner and outer wall separated by a vacuum for thermal insulation purposes. The outer tank provides the vacuum jacket and carries external atmospheric pressure, while the inner tank contains the cryogenic liquid hydrogen under the operating internal pressure. Weight trade studies were completed for different panel concepts and material systems (both metallic and composite). Extensive failure analyses were also performed for each combination of dimensional variables, materials, and layups to establish structural integrity of the various tank designs. Detailed stresses and strains were computed from operational temperature changes and pressure loads for both inner and outer tanks. Results demonstrate that composite materials (e.g., PMCs, and DRAs), with their tailorable stiffness and strength properties lead to lower mass outer tank designs as compared with traditional metal tank designs. Furthermore, Gr/Ep (i.e., IM7/977-2) based inner tank designs will exhibit microcracking due to thermally induced stresses. As a result Gr/Ep inner tank designs will require a liner material to ensure no hydrogen permeation (both through microcracking and thinness of gage), unless the nanoclay enhanced graphite/epoxy systems discussed in Sullivan et al. (ref. 2) are shown to be viable.

The final baseline estimated metallic based tank weight came in at about $153 \mathrm{lbs}$ for both inner (mostly unstiffened Al $2024=42 \mathrm{lb}$ ) and outer (bi-grid stiffened DRA 55 percent $=111 \mathrm{lb}$ ) tank walls. With the graphite/epoxy based design weight coming in at $160 \mathrm{lbs}$ for both inner (Gr/Ep with Al2024 liner $=51.8 \mathrm{lb}$ ) and outer (iso-grid stiffened $\mathrm{Gr} / \mathrm{Ep}=108 \mathrm{lb}$ ) tank walls. Note if the $\mathrm{Gr} / \mathrm{Ep}$ based tank design's inner tank is replaced with an all aluminum inner tank (i.e., Al 2024) the overall weight is decreased to $150 \mathrm{lb}$. Either composite/hybrid design is approximately 10 to 16 percent lighter than the lightest weight alternative all monolithic metallic design of $180 \mathrm{lb}$, inner tank (Al $2024=42 \mathrm{lb}$ ) and outer tank (bi grid LiAl $2090=138 \mathrm{lb}$ ). Note, although higher factors of safety and lower strain allowables were imposed in this study as compared with previous work (ref. 2), the final overall hybrid tank system weight (composed of an Al 2024 inner tank and Gr/Ep outer tank) was approximately $60 \mathrm{lb}$ lighter. This decrease in weight is mainly attributable to the fact that no minimum gage thickness was imposed in this study; with the result being a 3 times thinner inner tank wall thickness as compared to previous work (ref. 2). Clearly then weight growth is to be expected, due to minimum gage thickness either for manufacturing limitations or for hydrogen permeation requirements, as well as closeout details and items such as weld fillets, brackets, clips, etc. The final choice regarding which tank design would be selected will most likely be determined by manufacturing and inspectability costs and requirements.

\section{References}

1. Mital, S.K., Gyekenyesi, J.Z., Arnold, S.M., Sullivan, R.M., Manderscheid, J.M., and Murthy, P.L.N, "Review of Current State of the Art and Key Design Issues With Potential Solutions for Liquid Hydrogen Cryogenic Storage Tank Structures for Aircraft Applications, NASA/TM-2006-214346, October 2006.

2. Sullivan, R.M., Palko, J.L., Tornabene, R.T., Bednarcyk, B.A., Powers, L.M., Mital, S.K., Smith, L.M, Wang, X.J., and Hunter, J.E., "Engineering Analysis Studies for Preliminary Design of Lightweight Cryogenic Hydrogen Tanks in UAV Applications," NASA/TP_-2006-214094, May 2006.

3. Ashby, M.F., Materials Selection in Mechanical Design, 3rd ed., Elsevier Butterworth-Heinemann, Oxford, England, 2005.

4. Miracle, D.B., "Metal Matrix Composites for Space Systems: Current Uses and Future Opportunities. Affordable Metal-matrix Composites for High Performance Applications, Awadh B. Pandey, Kevin

L. Kendig, and Thomas, J. Watson, eds., TMS, Warrendale, PA, 2001, pp. 1-21.

5. Sharke, P., "Technology Focus. Fluid Handling and Fluid Power. $\mathrm{H}_{2}$ Tank Testing." Mechanical Engineering, April 2004. 
6. HyperSizer Structural Sizing Software, Collier Research Corp., Hampton, VA, http://www.hypersizer.com, 2006.

7. Federal Aviation Administration Regulation. FAR section 27.303. http://www.flightsimaviation.com/data/FARS/part 27-03.html, Accessed Mar. 16, 2006.

8. NASA Space Vehicle Design Criteria, NASA-SP8007 Buckling of Thin Walled Cylinders, National Aeronautics and Space Administration, Office of Advanced Research and Technology, Washington, D.C., August 1968.

9. Collier C. and Yarrington, P., "Consistent Structural Integrity in Preliminary Design," 46th AIAA/ASME/ASCE/AHS/ASC Structures, Structural Dynamics \& Materials Conference, Austin, TX, April 2005.

10. Collier, C., Yarrington, P., and Van West, B., "Composite, Grid-Stiffened Panel Design for Post Buckling Using HyperSizer," AIAA-2002-1222, 2002.

11. Arnold, S.M., Powers, L., and Glovan, R., "Design/Analysis and Manufacturability of Lightweight, Hybrid, Discontinuously Reinforced Aluminum Flat-Faced Propellant Duct Flanges," NASA/TM2004-213130, July 2004.

12. Mil-Hdbk-5, Metallic materials: DOD, pages 3-87 and 3-88.

13. Mil-Hdbk-17-3E, Composite materials: DOD Coordination Working Draft, 1998. 


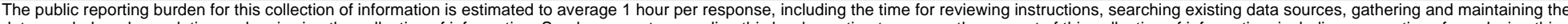

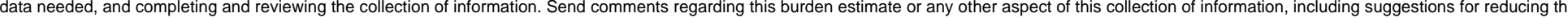

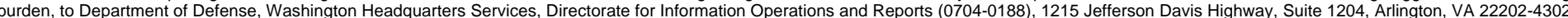

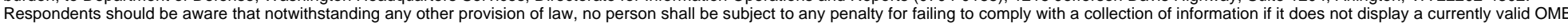
control number.

PLEASE DO NOT RETURN YOUR FORM TO THE ABOVE ADDRESS.

\section{REPORT DATE $(D D-M M-Y Y Y Y)$ \\ 2. REPORT TYPE \\ 3. DATES COVERED (From - To)}

01-08-2007

Technical Memorandum

\section{TITLE AND SUBTITLE}

Spherical Cryogenic Hydrogen Tank Preliminary Design Trade Studies
Arnold, Steven, M.; Bednarcyk, Brett, A.; Collier, Craig, S.; Yarrington, Phillip, W.

\section{AUTHOR(S)}

\section{5a. CONTRACT NUMBER}

5b. GRANT NUMBER

5c. PROGRAM ELEMENT NUMBER

\section{5d. PROJECT NUMBER}

5e. TASK NUMBER

5f. WORK UNIT NUMBER

WBS 561581.02.08.03.15.03

\section{PERFORMING ORGANIZATION}

REPORT NUMBER

E-16061

National Aeronautics and Space Administration

John H. Glenn Research Center at Lewis Field

Cleveland, Ohio 44135-3191

9. SPONSORING/MONITORING AGENCY NAME(S) AND ADDRESS(ES)

National Aeronautics and Space Administration

Washington, DC 20546-0001

\section{DISTRIBUTIONIAVAILABILITY STATEMENT}

Unclassified-Unlimited

Subject Categories: 24 and 39

Available electronically at http://gltrs.grc.nasa.gov

This publication is available from the NASA Center for AeroSpace Information, 301-621-0390

\section{SUPPLEMENTARY NOTES}

\section{ABSTRACT}

A structural analysis, sizing optimization, and weight prediction study was performed by Collier Research Corporation and NASA Glenn on a spherical cryogenic hydrogen tank. The tank consisted of an inner and outer wall separated by a vacuum for thermal insulation purposes. HyperSizer (Collier Research and Development Corporation), a commercial automated structural analysis and sizing software package was used to design the lightest feasible tank for a given overall size and thermomechanical loading environment. Weight trade studies were completed for different panel concepts and metallic and composite material systems. Extensive failure analyses were performed for each combination of dimensional variables, materials, and layups to establish the structural integrity of tank designs. Detailed stress and strain fields were computed from operational temperature changes and pressure loads. The inner tank wall is sized by the resulting biaxial tensile stresses which cause it to be strength driven, and leads to an optimum panel concept that need not be stiffened. Conversely, the outer tank wall is sized by a biaxial compressive stress field, induced by the pressure differential between atmospheric pressure and the vacuum between the tanks, thereby causing the design to be stability driven and thus stiffened to prevent buckling. Induced thermal stresses become a major sizing driver when a composite or hybrid composite/metallic material systems are used for the inner tank wall for purposes such as liners to contain the fuel and reduce hydrogen permeation.

\section{SUBJECT TERMS}

Modeling; UAVs; Cyrogenic hydrogen tanks

\begin{tabular}{|l|l|l|l|}
\hline \multicolumn{2}{|l|}{ 16. SECURITY CLASSIFICATION OF: } & $\begin{array}{l}\text { 17. LIMITATION OF } \\
\text { ABSTRACT }\end{array}$ \\
\begin{tabular}{|l|l|} 
a. REPORT \\
U
\end{tabular} & $\begin{array}{l}\text { b. ABSTRACT } \\
\text { U }\end{array}$ & $\begin{array}{l}\text { c. THIS } \\
\text { PAGE } \\
\text { U }\end{array}$ & \\
\hline
\end{tabular}

18. NUMBER
OF
PAGES
26

19a. NAME OF RESPONSIBLE PERSON
Steven M. Arnold
19b. TELEPHONE NUMBER (include area code)
216-433-3334



